\title{
The oxidation of limonene at raised pressure and over the various titanium-silicate catalysts
}

\author{
Agnieszka Wróblewska*, Edyta Makuch, Piotr Miądlicki \\ West Pomeranian University of Technology, Szczecin, Institute of Organic Chemical Technology, ul. Pulaskiego 10, \\ 70-322 Szczecin, Poland \\ "Corresponding author: e-mail: Agnieszka.Wroblewska@zut.edu.pl
}

\begin{abstract}
This work presents the studies on the oxidation of limonene with hydrogen peroxide and tert-butyl hydroperoxide (TBHP) in the presence of : TS-2, Ti-Beta, Ti-MCM-41 and Ti-MWW catalysts, at the autogenic pressure and atmospheric pressure. The examination were performed at the following conditions: the temperature of $140^{\circ} \mathrm{C}$ (studies in the autoclave) and $80^{\circ} \mathrm{C}$ (studies in glass reactor), the molar ratio of limonene/oxidant $\left(\mathrm{H}_{2} \mathrm{O}_{2}\right.$ or WNTB) $=1: 1$, the methanol concentration $80 \mathrm{wt} \%$, the catalyst content $3 \mathrm{wt} \%$, the reaction time $3 \mathrm{~h}$ and the intensity of stirring $500 \mathrm{rpm}$. The analysis of the results showed that in process not only 1,2-epoxylimonene was formed but also: 1,2-epoxylimonene diol, carveol, carvone and perillyl alcohol but for 1,2-epoxylimonene obtaining the better method was the method at the autogenic pressure and in the presence of TBHP.
\end{abstract}

Keywords: limonene oxidation, hydrogen peroxide, TBHP.

\section{INTRODUCTION}

Limonene is a cheap and an easy available compound. Its main source are orange peels which are the waste from the orange juices industry. This compound can be obtained from orange peels by the steam distillation, the simply distillation, the extraction with various solvents or by the cold pressing. Limonene has a lot of applications in various branches of industry. Among others it is used in cosmetic, perfume and food industries. In organic industry limonene is used as a biodegradable, and an environmentally friendly solvent for paints, varnishes and resins. Limonene has also antibacterial and antifungal properties and it is applied in the agriculture and in the veterinary medicine as a natural insecticide and a repellent. This compound has also applications in medicine because its strong antitumor activity (suppressing the growing of cancer cells of the cancer of: ripple, skin, liver, lungs and prostate $)^{1-5}$.

The main product of the process of limonene oxidation is 1,2-epoxylimonene. This very valuable compound is used in production of: paints, varnishes or protective coatings. This compound is also biologically active compound, thus it found applications in syntheses of various drugs. Moreover, 1,2-epoxylimonene is used in the cosmetic industry (as a component of smelling compositions) and in the food industry (for flavoring of food) ${ }^{6-7}$. This compound can be also used in syntheses of very valuable compounds for the organic and polymers industry. For example: Nguyen et al. described a method of carvone obtaining by the isomerization of 1,2-epoxylimonene ${ }^{8}$ and Byrne et al. showed the method of the synthesis of a special polymer (poly(limonene) carbonate) from 1,2-epoxylimonene and $\mathrm{CO}_{2}$ - this polymer has properties similar to polystyrene ${ }^{9}$. The applications of 1,2-epoxylimonene in medicine are also very important: a decreasing of the oxidative stress and curing of the anxiety states ${ }^{\mathbf{1 0}}$.

The other oxygenated derivatives of limonene which are also observed in the process of limonene oxidation (1,2-epoxylimonene diol, carveol, carvone and perillyl alcohol) are also very valuable semi-products which are used in: medicine (compounds having antitumor activity and antibacterial properties), agriculture (components suppressing sprouting of potatoes, pesticides acting as repellents against mosquitos, and antifungal compounds), chemical industry (production of household detergents), food industry (components of chewing gums, components of smelling compositions, and food additives), cosmetic industry (components of smelling compositions and soaps), perfume industry (components of smelling compositions) and organic syntheses of complex compounds, for example the synthesis of "quassine" terpenoide ${ }^{11-13}$.

There are only few reports on the utilization of titanium silicate catalysts in the oxidation of limonene. Only such titanium silicate catalysts were mainly applied in this process: Ti-MCM-41, Ti-MMM-2, Ti-SBA-15 and TS- $1^{2,14,15-20}$. The epoxidation of limonene over the Ti-MCM-41 was performed with hydrogen peroxide or tert-butyl hydroperoxide (TBHP) as the oxidizing agents. Several methods were used for the synthesis of the TiMCM-41 catalyst: direct - a sol-gel method in hydrothermal conditions (in-framework Ti-MCM-41) ${ }^{2}$, and post-synthesis methods: grafting (Ti-grafted MCM-41) ${ }^{15}$ or wetness and vet impregnation ${ }^{17}$. Also the structure of the Ti-MCM-41 catalyst obtained in the direct solgel method was silylated ${ }^{16}$. The studies over the above mentioned various Ti-MCM- 41 catalysts were performed at the temperatures of $70-85^{\circ} \mathrm{C}$, for the molar ratio of limonene $/ \mathrm{H}_{2} \mathrm{O}_{2}=3.7: 1$ and for the reaction time of $0.5-7 \mathrm{~h}$ (in one case from $1 \mathrm{~h}$ to $24 \mathrm{~h}^{15}$ ). Over the direct synthesised Ti-MCM-41 catalyst the selectivity of the epoxide compounds (the sum of 1,2- and 8,9-epoxylimonene) was about $60 \mathrm{~mol} \%$. Carveol and carvone were formed with the selectivity of $20 \mathrm{~mol} \%$, diepoxylimonene with the selectivity of about $10 \mathrm{~mol} \%$ and glycols with the selectivity of about $10 \mathrm{~mol} \%$. The conversion of limonene changed from 36 to $80 \mathrm{~mol} \%$. Over the silylated Ti-MCM-41 catalyst the results of limonene epoxidation were very close, and the only one difference was a higher value of hydrogen peroxide efficiency ${ }^{16}$. The two other methods of Ti-MCM-41 preparation (wetness and vet impregnation) do not cause any important changes in the catalyst activity ${ }^{17}$. The utilization of TBHP in the epoxidation of limonene causes that after the reaction 
time of $24 \mathrm{~h}$ the conversion of limonene was $62 \mathrm{~mol} \%$ and the selectivity of 1,2-epoxylimonene amounted to $75 \mathrm{~mol} \%$. Over the Ti-MMM-2 catalyst epoxidation of limonene was performed in acetonitrile as the solvent, at the temperature of $60^{\circ} \mathrm{C}$ and for the molar ratio of limonene $/ \mathrm{H}_{2} \mathrm{O}_{2}=1: 2^{\mathbf{1 4}}$. These studies showed that the amount of the obtained epoxide compound was three times higher than other products. Simultaneously, the amount of carvone was higher than carveol. In the postreaction mixtures also perillyl alcohol was detected ${ }^{\mathbf{1 4}}$. During the studies over the Ti-SBA-15 catalyst synthesized by grafting titanium on a SBA-15 structure two oxidizing agents were used: $\mathrm{H}_{2} \mathrm{O}_{2}$ and $\mathrm{TBHP}^{\mathbf{1 8 - 1 9}}$. The reaction was performed in acetonitrile for the reaction time to $24 \mathrm{~h}$. The following molar ratios of limonene/ oxidizing agent were used in these studies: the molar ratio of limonene $/ \mathrm{H}_{2} \mathrm{O}_{2}=1: 1.3$ and the molar ratio of limonene/TBHP $=1: 1.6$. For the reaction with $\mathrm{H}_{2} \mathrm{O}_{2}$ the temperature of $70^{\circ} \mathrm{C}$ and for TBHP the temperature of $80^{\circ} \mathrm{C}$ were used. For all investigated oxidizing agents the selectivity of 1,2-epoxylimonene was $100 \mathrm{~mol} \%$, but for $\mathrm{H}_{2} \mathrm{O}_{2}$ the conversion of limonene was $40 \mathrm{~mol} \%$, and for TBHP $60 \mathrm{~mol} \%$. The studies on the epoxidation of limonene over TS-1 and Ti-SBA- 15 were also showed in the work of Wróblewska ${ }^{20}$. These studies were performed at the atmospheric pressure with $60 \mathrm{wt} \% \mathrm{H}_{2} \mathrm{O}_{2}$ and in the presence of the TS- 1 and Ti-SBA-15 titanium silicate catalysts (TS-1 and Ti-SBA-15 catalysts were synthesized by the sol-gel method in hydrothermal conditions). The epoxidation was performed at the temperatures of: 0 , 40,80 and $120^{\circ} \mathrm{C}$. The reaction time was changed from 0.5 to $24 \mathrm{~h}$. During the examination the formation of the following product was observed: 1,2-epoxylimonene and its diol, perillyl alcohol, carvone and carveol. The studies showed a lot of differences in the epoxidation of limonene in the presence of TS-1 and Ti-SBA- 15 . First of all TS- 1 was the active catalyst in the process but higher values of the main functions describing the process were obtained for the Ti-SBA-15. For both catalysts the formation of carveol was observed but almost whole amount of carveol was converted to carvone independent of the temperature and the reaction time. The amount of carveol and carvone raised with the rising the temperature and with the prolongation of the reaction time. Perillyl alcohol was also formed and for almost all studied conditions it was the main product of the process ${ }^{20}$.

The aim of this work was the comparison of two method of limonene oxidation: at the autogenic pressure (at the raised pressure) and at the atmospheric pressure (taking into account the formation of appropriate products) over such titanium silicate catalysts as: TS-2, Ti-Beta, Ti-MCM-41, and Ti-MWW. Also the comparison the activity of these titanium silicate catalysts was presented. In these studies two oxidizing agents were used: hydrogen peroxide (60 wt $\%$ solution in water) and TBHP (5M solution in decane). Moreover, the effectiveness of these oxidants was compared.

\section{EXPERIMENTAL}

The TS-2 catalyst was prepared according to the method described by Reddy et al. ${ }^{21}$, the Ti-Beta by the method of Camblor et al. ${ }^{22}$, the Ti-MCM-41 catalyst by the method of Gruna et al. $^{23}$, and the Ti-MWW catalyst by the method of $\mathrm{Wu}$ et al. $^{24}$. The full characteristic of the obtained catalysts was presented in our previous works: TS-2 ${ }^{25-26}$, Ti-Beta ${ }^{25}$, Ti-MCM-41 ${ }^{25,27}$, Ti-MWW ${ }^{28}$.

In the epoxidation of limonene the following reactants were used: R- $(+)$-limonene (97\%, Sigma), hydrogen peroxide (60 wt \% water solution, Chempur), tert-butyl hydroperoxide (5M solution in decane, Sigma), and methanol (analytical grade, Chempur). The studies on the oxidation of limonene were carried out with hydrogen peroxide and TBHP as oxidants and with help of two methods: at the autogenic pressure and at the atmospheric pressure. At the autogenic pressure the oxidation was performed in the autoclave of Berghof company equipped with the TEFLON insert with the capacity of $150 \mathrm{~cm}^{3}$ and at the pressure of 10 bars. At the atmospheric pressure the studies were performed in the glass reactor with the capacity of $100 \mathrm{~cm}^{3}$ equipped with the reflux condenser, the thermometer and magnetic stirrer. The temperature was controlled by WIGO MS 11 HS apparatus with functions of stirring and heating. The oil bath was used for heating the reaction mixtures in the glass reactor. The conditions of the oxidation of limonene were as follows: the temperature of $140^{\circ} \mathrm{C}$ (the method at the autogenic pressure) and $80^{\circ} \mathrm{C}$ (the method at the atmospheric pressure), the molar ratio of limonene/oxidizing agent $\left(\mathrm{H}_{2} \mathrm{O}_{2}\right.$ or TBHP) $=1: 1$, the methanol concentration $80 \mathrm{wt} \%$, the content of the catalyst $3 \mathrm{wt} \%$, the reaction time $3 \mathrm{~h}$ and the intensity of stirring $500 \mathrm{rpm}$.

After the oxidation process the post-reaction mixtures were centrifuged (the separation of the catalysts) and then the obtained solutions were analyzed by the gas chromatography method and by the iodometric titration (the establishing of the unreacted hydrogen peroxide only in case oxidations with hydrogen peroxide). The GC analyses were made with help of FOCUS apparatus equipped the flame-ionization detector and fitted with the Restek Rtx-WAX $0.53 \mathrm{~nm}$ x $30 \mathrm{~m}$ x $1.0 \mu \mathrm{m}$ capillary column filled with polyethylene glycol. The parameters of the analyses were as follows: the pressure of helium $50 \mathrm{kPa}$, sensitivity of 100 , the temperature of the sample chamber $200^{\circ} \mathrm{C}$, the detector temperature $250^{\circ} \mathrm{C}$, the temperature of the thermostat was increasing according to the following program: isothermally at $60^{\circ} \mathrm{C}$ for $2 \mathrm{~min}$., an increase to $240^{\circ} \mathrm{C}$ at the rate of $15^{\circ} \mathrm{C} / \mathrm{min}$., isothermally at $240^{\circ} \mathrm{C}$ for $4 \mathrm{~min}$, cooling to $60^{\circ} \mathrm{C}$. Reaction products were also identified by the GC-MS at the same conditions as in the GC method. The results of the quantitative analyses help as to calculate the mass balances for each synthesis. On the basis of the mass balance the main functions describing the process were determined: the selectivities of the appropriate products, conversion of limonene, conversion of hydrogen peroxide and the selectivity of transformation to organic compounds in relation to hydrogen peroxide consumed (efficiency of hydrogen peroxide conversion). The ways of calculations of these main functions are presented below: 


$$
\begin{aligned}
& \mathrm{S}_{\text {product } / \mathrm{L}}=\frac{\text { amount of moles of product }}{\text { amount of moles of limonene consumed }} \cdot 100[\mathrm{~mol} \%] \\
& \mathrm{C}_{\mathrm{L}}=\frac{\text { amount of moles of limonene consumed }}{\text { amount of moles of limonene introduced }} \cdot 100[\mathrm{~mol} \%] \\
& \text { into reactor } \\
& \mathrm{C}_{\mathrm{H} 2 \mathrm{O} 2}=\frac{\text { amount of moles of } \mathrm{H}_{2} \mathrm{O}_{2} \text { consumed }}{\text { amount of moles of } \mathrm{H}_{2} \mathrm{O}_{2} \text { introduced }} \cdot 100[\mathrm{~mol} \%] \\
& \text { into reactor } \\
& \mathrm{S}_{\text {org. comp./H2O2 }}=\frac{\text { amount of moles of formed organic compounds }}{\text { amount of moles of } \mathrm{H}_{2} \mathrm{O}_{2} \text { consumed }} \cdot 100[\mathrm{~mol} \%]
\end{aligned}
$$

\section{RESULTS AND DISCUSSION}

The results of our studies showed that in process of limonene oxidation not only 1,2-epoxylimonene was formed but also other very valuable compounds, such as: 1,2-epoxylimonene diol, carveol, carvone and perillyl alcohol. The possible ways of the formation of these compounds are presented below:

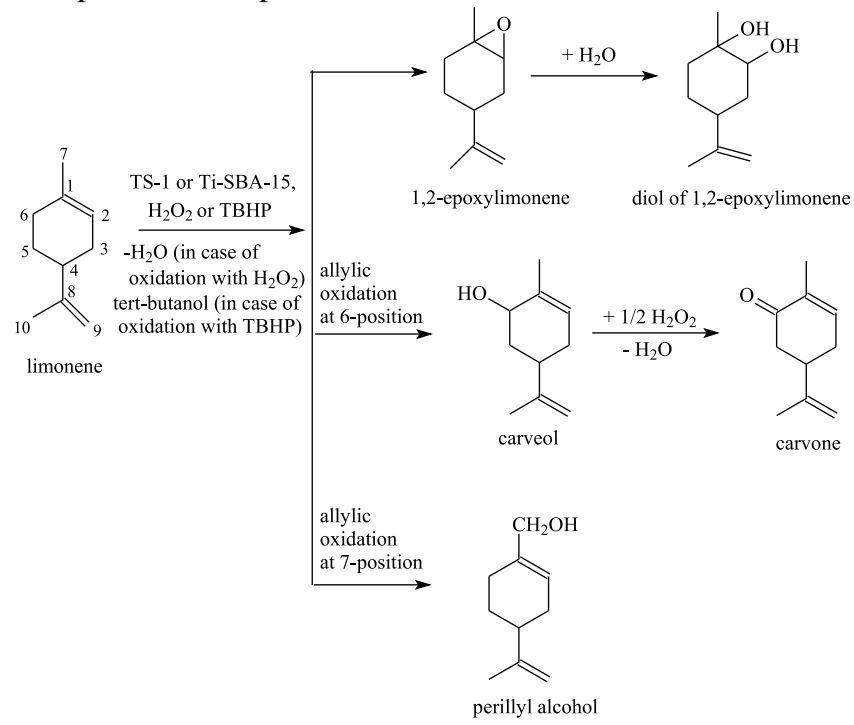

The results of the studies on the oxidation limonene at the autogenic pressure are presented in Figure 1 and in Table 1.

Figure 1 shows that for the studies with hydrogen peroxide and over the hydrophobic catalysts, such as: TS-2, Ti-MCM-41 and Ti-MWW, the selectivity of 1,2-epoxylimonene was lower than for the hydrophilic Ti-Beta catalyst (the hydrophilic character of this catalyst is connected with the presence of $\mathrm{Al}$ atoms in the

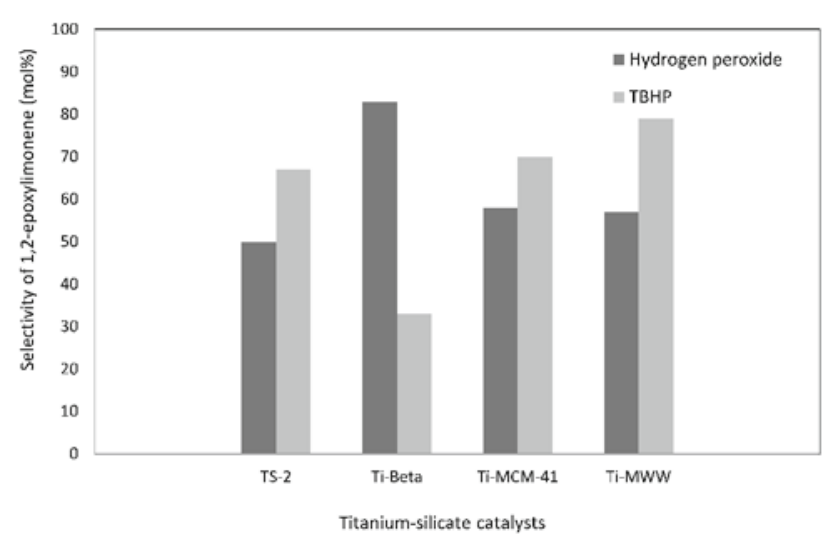

Figure 1. The influence of the kind of titanium silicate catalyst on the selectivity of 1,2-epoxylimonene during the studies at the autogenic pressure and for $\mathrm{H}_{2} \mathrm{O}_{2}$ and TBHP as oxidants

structure of silica). For TS-2, Ti-MCM-41 and Ti-MWW the selectivity of this epoxide compound amounted to from 50 to $57 \mathrm{~mol} \%$, and for Ti-Beta $83 \mathrm{~mol} \%$. For the examinations with TBHP the results were opposite. The hydrophilic Ti-Beta catalyst allowed to achieve the selectivity of the epoxide compound $33 \mathrm{~mol} \%$, and the hydrophobic catalysts (TS-1, Ti-MCM-41 and Ti-MWW) from 67 to $79 \mathrm{~mol} \%$. In general, the oxidation with TBHP allowed to obtain higher values of the selectivity of 1,2-epoxylimonene (excluding Ti-Beta catalyst). During the studies with hydrogen peroxide the size of the pores and Ti content of examined catalysts (Table 1) had a slight influence on the selectivity of epoxide compound (this function raised slightly - excluding Ti-Beta). During the studies with TBHP there was also visible a slight increase in values of the selectivity of 1,2-epoxylimonene during increasing the pore size and $\mathrm{Ti}$ content in the catalyst (excluding Ti-Beta). The different behavior of Ti-Beta catalysts during the presented research is probably mainly connected with the hydrophilic character of this catalyst.

Table 1 shows that for the studies with hydrogen peroxide the conversions of limonene was about 70-77 mol\% for TS-2 and Ti-MCM-41 catalysts, and 93-99 mol\% for Ti-Beta and Ti-MWW catalysts. It shows that the pore size and Ti content had not influence on the conversion

\begin{tabular}{|c|c|c|c|c|c|c|c|c|}
\hline Catalyst & $\begin{array}{c}\text { Pore size } \\
\text { [nm]/amount of } \\
\mathrm{Ti}[\mathrm{wt} \%]^{25,28}\end{array}$ & $\begin{array}{c}\mathrm{C}_{\mathrm{L}} \\
{[\mathrm{mol} \%]}\end{array}$ & $\begin{array}{c}\mathrm{S}_{1,2 \mathrm{EPDio} / \mathrm{L}} \\
{[\mathrm{mol} \%]}\end{array}$ & $\begin{array}{l}\mathrm{S}_{\text {carveol/L }} \\
{[\mathrm{mol} \%]}\end{array}$ & $\begin{array}{l}\mathrm{S}_{\text {carvone/L }} \\
\text { [mol\%] }\end{array}$ & $\begin{array}{c}\mathrm{S}_{\mathrm{PA} / \mathrm{L}} \\
{[\mathrm{mol} \%]}\end{array}$ & $\begin{array}{c}\mathrm{K}_{\mathrm{H} 2 \mathrm{O} 2} \\
{[\mathrm{~mol} \%]}\end{array}$ & $\begin{array}{c}\mathrm{S}_{\text {org. comp./H2O2 }} \\
{[\mathrm{mol} \%]}\end{array}$ \\
\hline \multicolumn{9}{|c|}{ Studies with $\mathrm{H}_{2} \mathrm{O}_{2}$} \\
\hline Ti-Beta & $0.74 / 1.2$ & 99 & 1 & 6 & 5 & 6 & 96 & 99 \\
\hline Ti-MCM-41 & $3.1 / 1.5$ & 77 & 5 & 8 & 8 & 20 & 75 & 97 \\
\hline Ti-MWW & $\begin{array}{c}0.4 \times 0.55 \\
0.71 \times 0.71 \\
0.71 \times 0.181 / 3.22\end{array}$ & 93 & 10 & 13 & 7 & 13 & 97 & 95 \\
\hline \multicolumn{9}{|c|}{ Studies with TBHP } \\
\hline TS-2 & $0.53 / 1.5$ & 40 & 0 & 5 & 0 & 8 & - & - \\
\hline Ti-Beta & $0.74 / 1.2$ & 49 & 0 & 13 & 1 & 19 & - & - \\
\hline Ti-MCM-41 & $3.1 / 1.5$ & 94 & 0 & 10 & 2 & 17 & - & - \\
\hline Ti-MWW & $\begin{array}{c}0.4 \times 0.55 \\
0.71 \times 0.71 \\
0.71 \times 0.181 / 3.22\end{array}$ & 17 & 0 & 4 & 0 & 0 & - & - \\
\hline
\end{tabular}
of limonene for epoxidation with hydrogen peroxide.

Table 1. The results of the studies on the oxidation of limonene with hydrogen peroxide and TBHP at the autogenic pressure (the values of the limonene conversion $\left(\mathrm{C}_{\mathrm{L}}\right)$, selectivity of 1,2-epoxylimonene diol $\left(\mathrm{S}_{1,2 \mathrm{EPDio} / \mathrm{L}}\right)$, selectivity of carveol $\left(\mathrm{S}_{\text {carveol/L }}\right)$, selectivity of carvone $\left(\mathrm{S}_{\text {carvone/L }}\right)$, selectivity of perillyl alcohol $\left(\mathrm{S}_{\mathrm{PA} / \mathrm{L}}\right)$, conversion of hydrogen peroxide $\left(\mathrm{K}_{\mathrm{H} 2 \mathrm{O} 2}\right)$ and selectivity of transformation to organic compounds in relation to hydrogen peroxide consumed $\left(\mathrm{S}_{\text {org. comp./H2O2}}\right)$ 
Moreover, the studies present that independent of hydrophilic character of Ti-Beta catalyst the 1,2-epoxylimonene was stable and did not undergo transformation to diol. A greater number of epoxide compound underwent transformation to diol over the remaining catalysts (about 5-10 mol\%). All catalysts were active catalysts in allylic oxidation at position 6 , thus the formation carveol and carvone was observed, but TS-2 and Ti-MWW were the most active materials. Over all titanium silicate catalysts formation of perillyl alcohol was observed, but the highest selectivities of this compound were observed for TS-2 and Ti-MCM-41 catalysts, respectively: 26 and $20 \mathrm{~mol} \%$. Conversion of hydrogen peroxide for TS-2, Ti-Beta, and Ti-MWW catalysts amounted to $96-97 \mathrm{~mol} \%$, only for Ti-MCM-41 it was lower and amounted to $75 \mathrm{~mol} \%$. The effective conversion of hydrogen peroxide was the highest for Ti-Beta, Ti-MCM-41 and Ti-MWW catalysts (95-97 mol\%), only for TS-2, which is characterized by the smallest pores, it amounted to $72 \mathrm{~mol} \%$.

Studies with the TBHP as oxidizing agent shows that the higher value of the limonene conversion was obtained for Ti-MCM-41 catalyst (94 mol\%) - the catalyst with the largest pores, for TS- 2 and Ti-Beta this function had value $40-49 \mathrm{~mol} \%$, and the lowest it had for the Ti-MWW catalyst. The formation of 1,2-epoxylimonene diol was not observed but carveol and carvone were detected in the post-reaction mixtures for all studied catalysts. The highest values of carveol selectivity were observed for Ti-Beta and Ti-MCM-41 catalysts. Moreover, it can be concluded that carveol molecules were more stable in the oxidation conditions and slower underwent oxidation to carvone than during the studies with hydrogen peroxide. The highest selectivities of perillyl alcohol were observed for Ti-Beta and Ti-MCM-41 catalysts (in contrast to the studies for hydrogen peroxide). Moreover, for the Ti-MWW catalyst the perillyl alcohol was not detected in the post reaction mixtures.

The results of the studies on the oxidation limonene at the atmospheric pressure are presented in Figure 2 and in Table 2.

Figure 2 shows that the selectivities of 1,2-epoxylimonene obtained during the studies at the atmospheric pressure are considerably lower than obtained for the oxidation at the autogenic pressure not only for hydrogen peroxide but also for TBHP. For the oxidation with

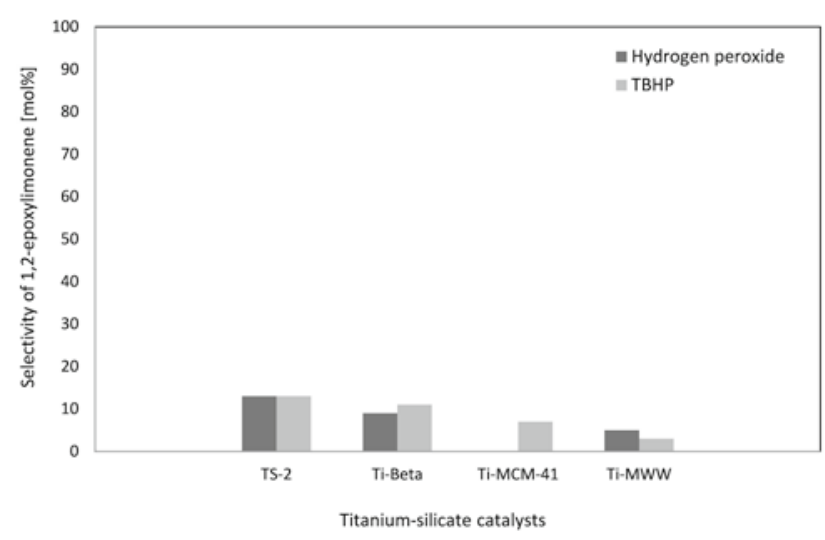

Figure 2. The influence of the kind of titanium silicate catalyst on the selectivity of 1,2-epoxylimonene during the studies at the atmospheric pressure and for $\mathrm{H}_{2} \mathrm{O}_{2}$ and TBHP as oxidants

hydrogen peroxide the highest value of the selectivity of the epoxide compound showed TS-2 catalyst, lower Ti-Beta and Ti-MWW (9 and $5 \mathrm{~mol} \%$ ) but in the presence of Ti-MCM-41 catalyst the formation of 1,2-epoxylimonene was not observed. During the studies with TBHP 1,2-epoxylimonene was form with the following selectivities: TS-2-13 mol\%, Ti-Beta $11 \mathrm{~mol} \%$, Ti-MCM-41 $7 \mathrm{~mol} \%$ and Ti-MWW $3 \mathrm{~mol} \%$. In general, the increase in the pore size and in the content of Ti of the studied materials causes decrease the selectivity of the epoxide compound independent of the used oxidizing agent.

Taking into account the results presented in Table 2 it is visible that for the method oxidation at the atmospheric pressure considerably lower conversions of limonene were obtained, for the oxidation with hydrogen peroxide 5-6 mol\%, and for oxidation with TBHP 4-5 mol\%. In comparison to the studies at the autogenic pressure, the oxidation at the atmospheric pressure is characterized by considerably higher values the selectivities of carveol and carvone, especially for studies with hydrogen peroxide where almost a half of the obtained carveol underwent oxidative dehydrogenation to carvone. Moreover, for these studies it is observed an increase in selectivity of carveol and a decreasing of carvone selectivity during increasing the pore size and $\mathrm{Ti}$ content of the studied catalysts. For the studies for TBHP the opposite tendency for selectivities of carveol and carvone was observed.

Table 2. The results of the studies on the oxidation of limonene with hydrogen peroxide and TBHP at the atmospheric pressure (the values of the limonene conversion $\left(\mathrm{C}_{\mathrm{L}}\right)$, selectivity of 1,2-epoxylimonene diol $\left(\mathrm{S}_{1,2 \mathrm{EPDio} / \mathrm{L}}\right)$, selectivity of carveol $\left(\mathrm{S}_{\text {carveol } / \mathrm{L}}\right)$, selectivity of carvone $\left(\mathrm{S}_{\text {carvone/L }}\right)$, selectivity of perillyl alcohol $\left(\mathrm{S}_{\mathrm{PA} / \mathrm{L}}\right)$, conversion of hydrogen peroxide $\left(\mathrm{K}_{\mathrm{H} 2 \mathrm{O} 2}\right)$ and selectivity of transformation to organic compounds in relation to hydrogen peroxide consumed $\left(\mathrm{S}_{\text {org. comp./H2O2}}\right)$

\begin{tabular}{|c|c|c|c|c|c|c|c|c|}
\hline Catalyst & $\begin{array}{c}\text { Pore size } \\
{[\mathrm{nm}] / \text { amount of } \mathrm{Ti}} \\
{[\mathrm{wt} \%]^{25,28}}\end{array}$ & $\begin{array}{c}\mathrm{C}_{\mathrm{L}} \\
{[\mathrm{mol} \%]}\end{array}$ & $\begin{array}{c}\text { S }_{1,2 \text { EPDiol/L }} \\
{[\mathrm{mol} \%]}\end{array}$ & $\begin{array}{l}\mathrm{S}_{\text {carveol/L }} \\
{[\mathrm{mol} \%]}\end{array}$ & $\begin{array}{l}\mathrm{S}_{\text {carvone/L }} \\
{[\mathrm{mol} \%]}\end{array}$ & $\begin{array}{c}\mathrm{S}_{\mathrm{PA} / \mathrm{L}} \\
{[\mathrm{mol} \%]}\end{array}$ & $\begin{array}{c}\mathrm{K}_{\mathrm{H} 2 \mathrm{O} 2} \\
{[\mathrm{~mol} \%]}\end{array}$ & $\begin{array}{c}\mathrm{S}_{\text {org. comp./H2O2 }} \\
{[\mathrm{mol} \%]}\end{array}$ \\
\hline \multicolumn{9}{|c|}{ Studies with $\mathrm{H}_{2} \mathrm{O}_{2}$} \\
\hline Ti-Beta & $0.74 / 1.2$ & 6 & 14 & 27 & 32 & 17 & 5 & 93 \\
\hline Ti-MCM-41 & $3.1 / 1.5$ & 5 & 15 & 35 & 37 & 13 & 6 & 69 \\
\hline Ti-MWW & $\begin{array}{c}0.4 \times 0.55 \\
0.71 \times 0.71 \\
0.71 \times 0.181 / 3.22 \\
\end{array}$ & 6 & 16 & 38 & 28 & 15 & 5 & 89 \\
\hline \multicolumn{9}{|c|}{ Studies with TBHP } \\
\hline TS-2 & $0.53 / 1.5$ & 5 & 0 & 28 & 25 & 34 & - & - \\
\hline Ti-Beta & $0.74 / 1.2$ & 5 & 0 & 23 & 30 & 36 & - & - \\
\hline Ti-MCM-41 & $3.1 / 1.5$ & 4 & 0 & 6 & 38 & 49 & - & - \\
\hline Ti-MWW & $\begin{array}{c}0.4 \times 0.55 \\
0.71 \times 0.71 \\
0.71 \times 0.181 / 3.22 \\
\end{array}$ & 4 & 0 & 12 & 39 & 46 & - & - \\
\hline
\end{tabular}


The increase of the pore size and Ti content caused the decrease in values of the selectivity of carveol and increase in values of the selectivity of carvone. The selectivity of perillyl alcohol slightly decreased during increase of the pore size and Ti content for studies with hydrogen peroxide (from 17 to $13-15 \%$ ). For studies with TBHP this selectivity raised with the increase the pore size and Ti content and reached the value from 34 mol\% to $46-49 \mathrm{~mol} \%$. Table 2 shows that conversion of hydrogen peroxide was very low and amounted for all studied catalysts 5-6 mol\%, but the effective conversion of hydrogen peroxide was similar to the obtained for the method at the autogenic pressure.

\section{CONCLUSIONS}

The used catalysts were found to be efficient catalysts for the oxidation of limonene to the corresponding products. The method at the autogenic pressure was more efficient, taking into account the selectivities of 1,2-epoxylimonene and conversions of limonene and hydrogen peroxide. On the other hand, in the second method (oxidation at the atmospheric pressure) high values of the selectivities of the other products of this process were obtained - carveol, carvone and perillyl alcohol. Thus, the method at the autogenic pressure can be used for 1,2-epoxylimonene obtaining with high selectivity, and the method at the atmospheric pressure for obtaining the other products of the oxidation of limonene which have also a lot of applications. The method at the atmospheric pressure needs further studies, especially the studies for longer reaction time should be performed. The presented method of limonene oxidation can be described as eco-friendly procedure, taking into account the mild conditions of its carrying out (atmospheric pressure or autogenic pressure, low temperatures) and the utilization of limonene which can be obtained from waste orange peels (biomass, renewable source). Moreover, hydrogen peroxide, which is used as the one from oxidizing agents, is cheap, mild and environmentally friendly oxidizing agent and the only product of its transformation is water.

\section{LITERATURE CITED}

1. Santa, A.M., Vergara, J.C., Palacio, L.A. \& Echavarria, A. (2008). Limonene epoxidation by molecular sieves zincophosphates and zincochromates. Catal. Today 2008, 133-135, 80-86. DOI: 10.1016/j.cattod.2007.12.025.

2. Cagnoli, M.V., Casuscelli, S.G., Alvarez, A.M., Bengoa, J.F., Gallegos, N.G., Samaniego, N.M., Crivello, M.E., Ghione, G.E., Pérez, C.F., Herrero, E.R., Marchettia, S.G. (2005). "Clean" limonene epoxidation using Ti-MCM-41 catalyst. Appl. Catal. A: General 287(2), 227-235. DOI: 10.1016/j.apcata.2005.04.001.

3. Pena, A., Veiga, S., Sapelli, M., Martinez, N., Marquez, V., Dellacassa, E. \& Bussi, J. (2012). Limonene oxidation by molecular oxygen under solvent-free conditions: The influence of peroxides and catalysts on the reaction rate. React. Kinet. Mech. Catal. 107, 263-275. DOI: 10.1007/s11144-012-0485-6.

4. Monteiro, J.L.F. \& Veloso, C.O. (2004). Catalytic conversion of terpenes into fine chemicals. Top. Catal. 27, 169-180. DOI: 1022-5528/04/0200-0169/0.

5. Rodrigues, S.N., Fernandes, I., Martins, I.M., Mata, V.G., Barreiro, F. \& Rodrigues, A.E. (2008). Microencapsulation of limonene for textile application. Ind. Eng. Chem. Res. 47 (12), 4142-4147. DOI: 10.1021/ie800090c.
6. Corma, A., Iborra, S. \& Velty, A. (2007). Chemical routes for the transformation of biomass into chemicals. Chem. Rev. 107, 2411-2512. DOI: 10.1021/cr050989d.

7. Arizaga, B., Leon, A., Burguen. N., Lopez, A., Paz, D., Martınez, N., Lorenzo, D., Dellacassa, E. \& Bussi, J. (2007). A clean process for the production of oxygenated limonene derivatives starting from orange oil. J. Chem. Technol. Biotechnol. 82, 532-538. DOI: 10.1002/jctb.1690.

8. Nguyen, T.T.T., Nguyen Chau, D.K., Duus, F. \& Le, T.N. (2013). Green synthesis of carvenone by montmorillonite-catalyzed isomerization of 1,2-limonene oxide. J. Org. Chem. 3, 206-209. DOI: 10.4236/ijoc.2013.33027.

9. Byrne, C.M., Allen, S.D., Lobkovsky, E.B. \& Coates, G.W. (2004). Alternating copolymerization of limonene oxide and carbon dioxide. J. Am. Chem. Soc. 126, 11404-11405. DOI: $10.1021 / \mathrm{ja} 0472580$.

10. Almeida, A.A.A., Carvalho, R.B.F., Silva, O.A., Sousa, D.P. \& Freitas, R.M. (2014). Potential antioxidant and anxiolytic effects of $(+)$-limonene epoxide in mice after marble-burying test. Pharmacol. Biochem. Behav. 118, 69-78. DOI: 10.1016/j. pbb.2014.01.006.

11. Almeida, A.A.A., Costa, J.P., Carvalho, R.B.F., Sousa, D.P. $\&$ Freitas, R.M. (2012). Evaluation of acute toxicity of a natural compound (+)-limonene epoxide and its anxiolytic-like action. Brain Res. 1448, 56-62. DOI: 10.1016/j.brainres.2012.01.070.

12. Gupta, A. \& Myrdal, P.B. (2004). Development of a perillyl alcohol topical cream formulation. Int. J. Pharm. 26, 373-383. DOI: 10.1016/j.ijpharm.2003.09.026.

13. Gupta, A., Stratton, S.P. \& Myrdal, P.B. (2005). An HPLC method for quantitation of perillyl alcohol in a topical pharmaceutical cream formulation. J. Pharm. Biomed. Anal. 37, 447-452. DOI: 10.1016/j.jpba.2004.02.039.

14. Bonon, A.J., Mandelli, D., Kholdeeva, O.A., Barmatova, M.V., Kozlov, Y.N. \& Shulpin, G.B. (2009). Oxidation of alkene and olefins with hydrogen peroxide in acetonitrile solution catalyzed by a mesoporous titanium-silicate Ti-MMM-2. Appl. Catal. A General 365, 96-104. DOI: 10.1016/j.apcata.2009.05.060.

15. Berlini, Ch., Guidotti, M., Moretti, G., Psaro, R. \& Ravasio, N. (2000). Catalytic epoxidation of unsaturated alcohols on Ti-MCM-41. Catal. Today 60, 209-225. DOI: 10.1016/ S0920-5861(00)00338-2.

16. Cagnoli, M.V., Casuscelli, S.G., Alvarez, A.M., Bengoa, J.F., Gallegos, N.G., Crivello, M.E., Herrero, E.R. \& Marchetti, S.G. (2005). Ti-MCM_41 silylation: development of a simple methodology for its estimation. Silylation effect on the activity and selectivity in the limonene oxidation with $\mathrm{H}_{2} \mathrm{O}_{2}$. Catal. Today 107-108, 397-403. DOI: 10.1016/j.cattod.2005.07.034.

17. Marino, D., Gallegos, N., Bengoa, J.F., Alvarez, A.M., Cagnoli, M.V., Casuscelli, S.G., Herrero, E.R. \& Marchetti, S.G. (2008). Ti-MCM-41 catalysts prepared by post-synthesis methods. Limonene epoxidation with $\mathrm{H}_{2} \mathrm{O}_{2}$. Catal. Today 133-135, 632-638. DOI: 10.1016/j.cattod.2007.12.111.

18. Chiker, F., Launay, F., Nogier, J.P. \& Bonardet, J.L. (2003). Green epoxidation on Ti-mesoporous catalysts. Environ. Chem. Lett. 1, 117-120. DOI: 10.1007/s10311-003-0031-x.

19. Chiker, F., Launay, F., Nogier, J.P. \& Bonardet, J.L. (2003). Green and selective epoxidation of alkenes catalysed by new $\mathrm{TiO}_{2}-\mathrm{SiO}_{2} \mathrm{SBA}$ mesoporous solids. Green Chem. 5, 318-322. DOI: 10.1039/B300244F.

20. Wróblewska, A. (2014). The epoxidation of limonene over the TS-1 and Ti-SBA-15 catalysts, Molecules 19, 19907-19992. DOI: 10.3390/molecules191219907.

21. Reddy, J.S., Kumar, R. \& Ratnasamy, P. (1990). Titanium silicalite-2: Synthesis, characterization and catalytic properties. Appl. Catal. A: General 58, L1-L4. DOI: 10.1016/ S0166-9834(00)82273-3.

22. Camblor, M.A., Corma, A. \& Perez-Pariente, J. (1993). Synthesis of titanoaluminosilicates isomorphous to zeolite Beta, active as oxidation catalysts. Zeolites 13, 82-87. 
23. Grun, M., Unger, K.K., Matsumoto, A. \& Tsutsumi, K. (1999). Novel pathways for the preparation of mesoporous MCM-41 materials: control of porosity and morphology. Micropor. Mesopor. Mater. 27, 207-216.

24. Wu, P., Tatsumi, T., Komatsu, T. \& Yashima, T. (2001). A novel titanosilicate with MWW structure. I. Hydrothermal synthesis, elimination of extraframework titanium, and characterizations. J. Phys. Chem. B 105(15), 2897. DOI: 10.1021/ jp002816s.

25. Wróblewska, A. (2008). Epoxidation of allylic compounds with hydrogen peroxide and in the presence of the titanium silicate catalyst. Szczecin, Poland: Publishing House of Technical University of Szczecin (in Polish).

26. Wróblewska, A. (2006). Optimization of the reaction parameters of epoxidation of allyl alcohol with hydrogen peroxide over TS-2 catalyst. Appl. Catal A: General 309, 192-200. DOI: 10.1016/j.apcata.2006.05.004.

27. Wróblewska, A., Fajdek, A., Wajzberg, J. \& Milchert E. (2009). Epoxidation of allyl alcohol over mesoporous Ti-MCM-41 catalyst. J. Hazard. Mater. 170, 405-410. DOI: 10.1016/j.jhazmat.2009.04.082.

28. Wróblewska, A., Fajdek, A., Milchert, E. \& Grzmil, B. (2010). The Ti-MWW catalyst - its characteristic and catalytic properties in the epoxidation of allyl alcohol by hydrogen peroxide. Pol. J. Chem. Technol. 12(1), 29-34. DOI: 10.2478/ v10026-010-0006-1.

29. Golowa, B.M., Motowiljak, L.W., Politanskij, S.F., Stjepanow, M.W. \& Czeljadin, W.T. (1974). The establishing the products in the process of glycerol obtaining during the epoxidation of allyl alcohol. Zawod. Lab. 40, 1192-1194. (in Russian). 